\title{
АСОЦІАТИВНИЙ ПОТЕНЦІАЛ КОНЦЕПТУ МОЛОДІСТЬ (на матеріалі сучасного англомовного художнього дискурсу)
}

\author{
Ольга Бешлей \\ Чернівецький національний університет імені Юрія Федьковича, \\ вул. Кочююбиського, 2, м. Чернівиі, Україна, 58012 \\ o.beshlei@chnu.edu.ua
}

Статтю присвячено висвітленню асоціативних значень у структурі змістового наповнення концепту МОЛОДІСТЬ на підставі текстової інтерпретації фрагментів сучасного англомовного прозового дискурсу, в яких устами героїв відтворені асоціації, оцінки, емоції та переживання, ситуативно пов'язані із молодістю як віковою категорією. Асоціативний діапазон представлений аксіологічно маркованими асоціативними кореляціями досліджуваного концепту з базовими (СТАРІСТЬ, УСПІХ), емотивними (КОХАННЯ, ЩАСТЯ, СМУТОК), соціокуЛьтурними (КУЛЬТ, СВОБОДА, ПРОТЕСТ, КРИЗА) й естетичним (КРАСА) концептами. Засобами вербалізації є субстантивна лексема youth (молодість) та атрибутивна лексема уoung (молодий). Текстовий аналіз дав можливість виокремити низку інваріантних компонентів асоціативного діапазону концепту МОЛОДІСТЬ, сформованих на тлі тісної кореляції з концептом СТАРІСТЬ. Серед них: бажання утримати/повернути молодість, різке неприйняття усіх виявів старості, неспроможність зберегти молодість, трагедія і біль їі утрати, криза особистості, конфлікт поколінь.

Ключові слова: асоціативні кореляції, концепт, художній дискурс, імпліковане / експліковане значення, аксіологічне маркування.

Вступ. У контексті когнітивної лінгвістики, де зв'язок мови зі свідомістю постає фокусом дослідження, особливо перспективним є висвітлення значущих культурних констант - концептів, які несуть аксіологічне смислове навантаження, слугують підставою для формування суспільних стереотипів та відкривають асоціативний потенціал для представників мовної спільноти [13, с. 18]. Це створює передумови для вивчення молодості як соціокультурного феномена, характеристики і функції якого модельовані директивами суспільства, в якому він існує. Об'єктом наукових пошуків постає концепт МОЛОДІСТЬ як один із ключових концептів вікової семантики, актуалізований у сучасному англомовному художньому прозовому дискурсі крізь призму типових асоціативних кореляцій у структурі його змістового наповнення.

Аналіз останніх досліджень і публікацій. Поняття молодість людини як соціально-культурнацінність розглядалось у працях античних мудреців і досі перебуває у фокусі досліджень філософів [18], психологів [4] та соціологів [20; 21]. Зміни ціннісних орієнтирів сучасного соціуму стимулюють необхідність переосмислення сутності і ролі молодості. У соціальному вимірі молодість вважається найціннішим віковим періодом. Стереотипи поведінки молоді часто стають характерною

(C) Бешлей O, 2020 
особливістю нації. На цю соціальну групу орієнтуються політики, підприємці, діячі мистецтва. Приміром, Б. С. Волков стверджує, що “у молодості людина проявляє найвищий рівень творчості, схильна до переосмислення світу і свого місця в ньому; у всі свої справи і починання вкладає велику енергію. При цьому, невдачі в починаннях переживаються важко" [4, с. 68]. Пошук сенсу життя в молодості пов'язують зі створенням власної частки культури і середовища. Для сучасного молодого покоління важливий результат діяльності, а саме досягнення бажаного соціального статусу, прояв незалежності, здобуття освіти і кар'єри.

У рамках мовознавчих студій молодість входить до числа концептів вікової парадигми, які останнім часом регулярно привертають увагу дослідників. Наукові пошуки присвячені вивченню особливостей їхньої реалізації в англійській [11], німецькій [12], французькій [8], російській [5] та інших мовних картинах світу. Окремі роботи зосереджені на таких аспектах: актуалізації геронтологічних категорій молодість і cmapicmb в англійській мові [16]; порівняльному аналізі засобів вербалізації концепту ВІК у різноструктурних мовах [17]; представленні словотворчих особливостей лексем старий/молодий у російській мові [3]; відтворенні аксіологічного змісту геронтологічних категорій в англійській мові [1]; об'єктивації вікових концептів у контексті англійських фразеологізмів, афоризмів і паремій [7].

Незважаючи на численні лінгвістичні розвідки у сфері вікової семантики, концепт МОЛОДІСТЬ досі не поставав окремою культурною константою у рамках лінгвокультурологічного і лінгвокогнітивного напрямів, що посилює актуальність запропонованого дослідження.

Мета дослідження - визначити асоціативний потенціал концепту МОЛОДІСТЬ на тлі кореляцій 3 іншими концептами у площині сучасного британського та американського художнього прозового дискурсу. Ця мета передбачає постановку i вирішення таких завдань: ідентифікувати дискурсивні фрагменти 3 описом молодості, систематизувати їх відповідно до тематики, здійснити інтерпретаційнотекстовий аналіз з метою виявлення асоціативних кореляцій, простежити особливості профілювання концепту у системі базових концептів, змоделювати його структуру. Матеріалом дослідження $є$ прозові тексти жанрового різновиду соціальнопобутового і підліткового романів великої епічної форми сучасних британських та американських авторів (I. Banks, J. Barnes, J. Franzen, N. Gaiman, D. Mitchell, J. Picoult, N. Sparks, D. Steel). Доцільно зауважити, що в індивідуальному розумінні і в контексті художнього твору концепт МОЛОДІСТЬ ідентифікується по-різному. Розглянемо думки дослідників $з$ цього приводу.

Сучасний британський художній дискурс - це відлуння радикальних змін. Внутрішні і міжособистісні конфлікти, роздуми про своє призначення у світі - ось найпоширеніші “молодіжні” теми. У сучасних американських творах молодість представлена крізь призму життєвих орієнтирів молоді. 3 одного боку, це бажання бути особливим, успішним, безкомпромісним, стильно виглядати; з іншого, фіксуємо такі ознаки, як лінь, песимістичність настроїв, небажання працювати [19]. Згадані аспекти слугують планом вираження концепту МОЛОДІСТЬ у сучасній британсько- 
американській літературі і на семантичному рівні відображені відповідними словамисупровідниками.

Покладаючись на думку про те, що “статусно-рольова характеристика віку пов'язана зі стереотипним образом, закріпленим за ним у суспільстві і репрезентована передбачуваними векторами асоціацій” [14, с. 141], висуваємо таку гіпотезу: характер варіативності асоціативних кореляцій концепту відтворює зв'язок між його мовним вираженням і сприйняттям дійсності.

Методологія дослідження. У роботі виходимо із запропонованих Ю. Степановим положень про те, що концепт є основною зв'язною ланкою для відтворення культури в ментальному світі людини, результатом прояву емоцій, симпатій і антипатій, а іноді й конфліктів $[15$, с. 8$]$. Такі передумови дають підставини розглядати концепт МОЛОДІСТЬ як динамічне утворення, що належить до соціальних, економічних й естетичних цінностей і реагує на усі коливання у суспільстві. Важливим вважаємо нижченаведене твердження Н. Крючкової: "Концептуальна інформація, прихована за мовними одиницями з віковим значенням, може використовуватися в дискурсі як один із дуже дієвих способів формування оцінки висловлювання. При цьому, автор тексту ніби впроваджує фактичну інформацію в концептуальну, змушуючи таким чином читача оцінювати явища крізь призму концепту” [8, с. 17]. Відтак, змістове наповнення концепту МОЛОДІСТЬ залежить від об'єктивних і суб'єктивних оцінок, які потребують інтерпретації у текстовому вимірі і визначаються 'зсередини' (як самооцінка суб'єкта дискурсу) і ‘зовні' (зі сторони, тобто авторська думка). Їхнє входження у семантику має асоціативну природу.

У когнітивній лінгвістиці асоиіаціï розглядають як моделі зберігання знань у пам'яті, невипадкові зв' язки ідей та уявлень, що зумовлені відображенням у свідомості взаємодії предметів і явищ дійсності [6, с. 15]. Іншими словами, “асоціативний діапазон концепту має значення, яке виходить за межі досліджуваного концепту, і в той же час запозичує значення інших концептів" [10, с. 18]. Наприклад, молодість як етап у житті людини може заміщувати явище, подію чи діяльність у процесі формування асоціативних зв'язків між елементами дійсності, які ситуативно пов'язані з досвідом мовця. Вивчення таких 'асоціативних мереж' у межах імплікованих/експлікованих значень концепту дає змогу розкрити гносеологічний аспект його змісту.

У рамках запропонованого дослідження враховуємо синкретичне існування абстрактного (молодість як вікова категорія) та конкретного (молодь як вікова група) референтів у межах одного мовного знака (англійський відповідник уоuth). Виходимо iз положення, що образ молоді імплікується в устах героїв творів через асоціації, пов'язані з молодістю.

Для розкриття асоціативного потенціалу концепту МОЛОДІСТЬ використовуємо чітко окреслений мовний інструментарій, представлений сполучуваністю номінативних лексем 3 аксіологічно маркованими словами-супровідниками, що відображають векторну шкалу опозиції у напрямку до сфер позитивного / негативного.

Окреслимо діапазон вибірки: до уваги беремо текстові фрагменти, що містять номінативні лексеми концепту (youth / young); в яких сюжетно розгортаються події, асоціативно пов'язані із молодістю (уоиth) як віковою категорією; які 
позначають аксіологічне марковане ставлення героя. У рамках вербального контексту опрацьовуємо номінативні лексеми як у вільних, так і в сталих словосполученнях. Фрагменти дискурсу можуть прирівнюватися реченню, кільком реченням чи цілісному текстовому уривку, які утворюють окреслені зони занурення концепту. Ці умови дають достатні підстави для проведення розрахунків. Аналіз мовних засобів у тексті, опираючись на твердження I. А. Бехти, проводимо у напрямку “від смислу тексту до значення слова" [2, с. 101]. Інтерпретаційний аналіз текстових фрагментів здійснюємо 3 урахуванням різноплановості аксіологічних характеристик, що відповідно вказує на варіативність асоціативних зв' язків концепту.

Результати дослідження та їхне обгрунтування. Відзначимо, що у площині тексту концепт розглядаємо насамперед як авторське знання, що відображає опосередковану героями творів інтерпретацію соціокультурного досвіду, пов' язаного 3 молодістю, й актуалізується як динамічний спектр аксіологічно маркованих асоціацій. У контексті асоціативних зв'язків між концептом МОЛОДІСТЬ та аксіологічними концептами ДОБРО (сфера позитивного аксіологічного маркування) і ЗЛО (сфера негативного аксіологічного маркування) аналізуємо кореляції із базовими (ЧАС, СТАРІСТЬ, УСПІХ, МРІЯ, НАДІЯ), естетичними (КРАСА, ТВОРЧІСТЬ), емОТИвНИМИ (ЩАСТЯ, РАДІСТЬ, КОХАННЯ, СМУТОК) соціокультурними (КУЛЬТ, СВОБОДА, ПРОТЕСТ, КРИЗА) концептами (назви за А. П. Мартинюк [9, с. 51]), які у дискурсі переплітаються або об'єктивуються на тлі один одного.

Зважаючи на те, що МОЛОДІСТЬ входить у парадигму вікових концептів, передбачуваною $є$ тісна кореляція 3 концептом СТАРІСТЬ [16], що слугуватиме основою формування більшості асоціативних зв'язків 3 іншими концептами. Статистично на життя людини відводять у середньому двадцять п'ять тисяч днів. Відтак, протягом століть людство прагне збільшення терміну тілесного буття. Історія дає приклади численних спроб знайти 'еліксир вічної молодості'. Стародавні греки, зокрема, пили амброзію для збереження молодості. 3 міфології відома історія нещасного Тітона, якому на прохання богині світла Ео дарували безсмертя, але не дали вічної молодості. Існує міф про чарівницю Медею, яка вміла повертати молодість. Середньовічні алхіміки шукали “філософський камінь”, що дарує молодість. Цього прагнув легендарний Фауст. Мотив омолодження - улюблений сюжет казок багатьох народів.

Сучасна література продовжує використовувати мотив вічної молодості. Молодість душі не порівнюють із реальним біологічним віком людини. Вона залежить від характеру, душевного настрою, сприйняття світу і за умови активної життєвої позиції може зберігатися порівняно довго. У літньому віці таке явище допомагає зберегти здатність відчувати й переживати емоції, регулярно зіставляють зі здатністю мріяти й уявляти. Головний герой наступного твору переконаний, що молодість душі - єдина коштовність, яку не в силі і не в праві забрати ні час, ні обставини, ні старість. Усе залежить тільки від власної мотивації і налаштування: He finally accepted he needed glasses. The bald patch on his head was the size of a bath plug-hole. He felt the restlessness of youth and the last-chance urgency of age at the same time. He was fifty-six years old, 
but he felt like eighteen [22]. Як бачимо, навіть у майже 60 можна відчувати себе на 18. Головне - це ставлення до себе й довколишнього світу. Подібні текстові фрагменти вказують на асоціативну кореляцію між концептами МОЛОДІСТЬ і СТАРІСТЬ.

Схожий зміст передано у такому фрагменті: And at 50 I feel like a youth again. My life is behind me and that hour, when I almost felt like a twenty-year-old youth, was the last burst of flame [23]. Автор ніби намагається 'омолодити' своїх вже не зовсім молодих героїв, надаючи їм відповідні риси та повертаючи їх спогадами у часи молодості. Протистояння теперішнього і минулого втілюється у бажанні повернути молоді роки. На мовному рівні зіставлення відображено за допомогою прийменників like або сполучника порівняльної семантики as. Зазвичай порівняння одночасно актуалізується у поєднанні з оцінним компонентом.

Цікавою особливістю сучасних англомовних творів є зміна ракурсу у відображенні бажання героїв утримати молодість. Темп сучасного суспільства перетворює наше життя на суцільну гонитву. Проблема загострюється тим, що кінцева мета таких перегонів не має єдиної форми існування - натомість, модифікується під тиском соціокультурного й економічного середовища. Більшість людей губиться на такому роздоріжжі. Культ молодості - тренд XXI століття, унікальна панацея від усіх невдоволень і страхів, що здатна подолати як зовнішніх, так і внутрішніх демонів. Розглянемо такий приклад: They were in an industry that prized youth. They had that in common, the fact that they were both struggling to accept how old they were and what it meant in their current lives. And both of them worked and lived in a culture based on youth. It wasn't easy getting older surrounded by people half their age who were itching to step into their shoes. She was constantly aware of it in her work. She has stayed on top for her entire career. She had to compete her peers, younger women, and she's still the best and the biggest in the business [29]. У наведеному текстовому фрагменті професійна зайнятість - лише змагання за звання наймолодшого, а кар'єра залежить від того, наскільки молодо виглядаєш (compete her peers, younger women). Додає вогню колегіальне оточення, представлене переважно молодим поколінням, яке безперестанку 'наступає на п’яти'. На тлі кореляції між концептами МОЛОДІСТЬ і СТАРІСТЬ паралельно простежуємо асоціативні зв'язки з концептами УСПІХ, ЩАСТЯ, КУЛЬТ, представлених лексичними конструкціями (industry that prized youth, culture based on youth).

Сучасні автори часто пропагують моду на молодість. Політики хочуть залишатись молодими, аби відчувати силу впливу, актори - аби гарно виглядати на екрані, знаменитості - для достойного показу себе протягом відвідування різноманітних масових заходів. Часто молоде обличчя - це божественна ознака 'непідробленого' небожителя. Наприклад: This is a most elegant assembly. I do not know when I last saw so many handsome faces and graceful figures gathered in one place. And every one of them in the utmost bloom of youth. I am surprized to see no older people in the room. Who would want to look at aged and unsightly persons to his ball? Besides we are not so young as you suppose. Just pretending [25]. У фрагменті спостерігаємо спробу героїв немолодого віку навмисно зберегти зовнішні ознаки молодості (not so young ... Just pretending) задля належного виконання окреслених соціальних ролей. Лексичні акценти (utmost 
bloom of youth, handsome faces, graceful figures) вкотре вказують на кореляцію між концептами МОЛОДІСТЬ, УСПІХ і КРАСА.

Бажання залишатись молодим настільки поширене, що навіть у кіноіндустрії пропагується ідеалізоване уявлення про те, як молодість 'має виглядати', про ії основні атрибути і норми поведінки: It was one of those movies that had come out after American Pie, hoping to make the same box office by taking naked girls and daredevil guys and what Hollywood imagined teenage life to be like [27]. У фрагменті засоби вербалізації (naked girls, daredevil guys) фіксують імплікацію негативної оцінки насаджування штучних образів (Hollywood imagined teenage life).

Ще одним вагомим постулатом сучасних засобів масової інформації є розкриття таємниці продовження молодості. Хірургічна пластика $є$ найпопулярнішим ‘еліксиром' молодості XXI століття. У дискурсі це явище експліцитно постає у контексті американського соціуму разом 3 усіма його 'благотворними' властивостями і позитивними результатами як в особистому, так і професійному ракурсі: Valerie did everything she could to confuse them. She had had the surgery done for the first time when she turned forty and then again fifteen years later. The results were excellent. She had also had her neck done when she was fifty, giving her a smooth, youthful neckline with no sag, and her plastic surgeon agreed that botox shots four times a year added to her youthful looks. It took time, effort and money to maintain her appearance. It served her vanity, but it was also important for her career. She was the number-one guru of style during a thirty five-year career [29]. Розглянемо детальніше сюжетну лінію. Автор експліцитно описує кожен крок процедури, іï мету і результативність. "Виправлення ситуації” проходить у кілька етапів і концентрується на окремих "зонах": очі, шкіра, шия, обличчя (had her eyes done, neck done, a smooth, youthful neckline, Botox shots). Результати говорять самі за себе - youthful looks, excellent, terrific, the effect she wanted. Зазначається, що важливо не переступити межу. Трохи більше пластики - ніхто не повірить у "натуральність" молодості. Однак загалом це чудовий спосіб зберегти відчуття першості, яке необхідне для успішної кар'єри (important for her career), підтримки відповідного рівня самооцінки (served her vanity) і статусу у суспільстві (numberone guru of style). Такі контексти відображають тісну кореляцію між концептами МОЛОДІСТЬ і УСПІХ. Молодість сприймають швидше як атрибут, аніж віковий період, це запорука і гарантія успіху. Залишатись молодим означає бути конкурентоспроможним як на ринку праці, так і в плані особистого розвитку.

Проблема збереження молодості не єдина, що носить асоціативний характер на текстовій площині. Своє втілення знаходять також відчайдушні спроби героїв повернути молодість. Це завдання порівняно нелегке. Традиційним способом вважається любов. Щойно заселившись у людському серці, вона оживляє зів'ялу 'квітку молодості': She made him feel young again. He hadn't realized how much he had been missing from his life until he fell in love with her. Just having dinner with her made him feel like a boy again, and the time they spent in bed drove him out of his mind. What he shared with her was a passion [29]. Відтак, простежуємо асоціативну кореляцію між концептами МОЛОДІСТЬ і КОХАННЯ. 
На жаль, час нестримний і непідвладний людському его, тому трагедія втрати молодості крізь століття залишається вельми актуальною. Змінились епохи і засоби, але ідея незмінна. Розглянемо такий фрагмент: Our faces marked by toil, by success, by love. Our weary eyes, looking anxiously for something out of life, that while it is expected is already gone - has passed unseen - together with the youth, strength, with the romance of illusions [26]. Попри усі здобутки, досягнуті вершини на життєвій стежині, у кінці шляху людина усвідомлює, що вже не повернути найголовнішого - років. Час залишає свій відбиток не тільки на обличчі (faces marked by toil, weary eyes), але й у душі, осідаючи далеко на дні гірким болем (already gone, passed unseen) від неспроможності повернути минуле. Асоціативний зв’язок між концептами МОЛОДІСТЬ і СМУТОК відзначається високим рівнем частотності відтворення у дискурсі.

Схожий вектор значень відтворює такий фрагмент: Old age would not continue the manifold pleasures of youth but would instead be a long trial that slowly robbed life of even its smallest, simplest joys [28]. Судячи з мовлення головного героя, втрата молодості прирівнюється до втрати радості життя. Асоціативний потенціал передано в одвічному протистоянні старості і молодості, у тих перевагах і недоліках, які вони передбачають. Без молодості життя людини перетворюється на довгий судовий процес (long trial), старість 'обкрадає' його (robbed life), забираючи найцінніше задоволення (joys, pleasures). На тлі емоційних переживань формується асоціативний зв’язок між концептами МОЛОДІСТЬ і ЩАСТЯ.

Трагедія втрати молодості для героя наступного текстового уривку виражається у суттєвому погіршенні різних аспектів здоров'я: He had crawled home from the office and gone to bed. There were no twenty-two-year-old models to help him celebrate his fiftieth birthday. He was in bed, in agony, watching TV. He was in mourning for his youth. Fifty had turned out to be just as bad as he had feared it would be, and worse [29]. У тексті через роздуми героя про його власне інтерпретування переваг молодості імплікується позитивна оцінка. Як і в більшості випадків, герої сумують за молодечими роками (mourning for his youth), що відтворено через призму кризи особистості. Вербальне обрамлення відтворює негативну оцінку старості (in agony, just as bad, worse) i доводить наявність асоціативної кореляції між віковими концептами.

Збільшення престижу молодості у сучасному світі значною мірою зумовило абсолютне неприйняття старості, що посилює аргументи на користь наявності асоціативного зв'язку між відповідними віковими концептами в сучасній англомовній літературі. Яскравим прикладом слугує такий контекст: She thought about her birthday again. Her mother had always loved the fact that they were born on the same day, but it had always annoyed April as a child. She hated sharing "her day" with someone else, but now that she was older, she didn't mind. She already knew that this year was going to be hard for her mother. She had been dreading turning sixty. And if April felt a little skittish about turning thirty, she could only imagine how much worse it was for her mother, whose success rested on her image of youth [29]. Фрагмент передає роздуми героїні щодо іiі стосунків із матір'ю. Вона ділиться з читачем емоціями (always annoyed April as a child, hated), які переживає маленька дівчинка, коли святкує (sharing “her day" with someone else) раз у рік своє день народження в один день із матір'ю. У процесі дорослішання 
ці відчуття зникають, однак складнішим цей процес стає для іiі матері (this year was going to be hard for her mother), яка так відчайдушно намагається замаскувати власні роки і надовше залишатися у статусі молодої жінки, навіть попри те, що їй уже 60 (dreading turning sixty). Здавалося б звична річ - пора підводити підсумки пройденого шляху. Але не у випадку, коли вся кар'єра побудована на поклонінні культу молодості (success rested partly on her image of youth).

Втрата колишньої молодечої краси і життєвої сили може обернутися страшною особистою трагедією: You're only young once, and I gave him my youth and then, when I wasn't young anymore, he broke his promises. I knew he would betray me. Then he slept with my best friend to hurt me. When I was struggling with my career, he abandoned me [24]. Героїня жалкує за втраченою молодістю, що, на ії думку, стало причиною зради чоловіка і руйнування їхнього шлюбу (betray, broke promises, abandoned). Запропонований контекст несе негативне аксіологічне маркування, підсилене емоційним фоном і демонструє кореляцію між концептами МОЛОДІСТЬ і КРИЗА.

Кореляція згаданих концептів відображена у дискурсі кризою особистості, що нерідко трапляється у молодому віці у процесі пошуку власного “я”, а також кризою традииій, коли молоде покоління сприймається як символ руйнування усталеної моралі. Зокрема, молодість - це завжди період випробувань, коли мрії розбиваються об гірку реальність: Stop burying yourself alive. Why does that make it right to waste the bloom of your youth serving cocktails for the enrichment of the drug dealer? [26]. Нерідко таке явище пов'язане із тим, що людина збивається зі шляху у пошуках свого призначення, відходить від власних цілей і продовжує плисти за течією замість того, щоб брати від життя по максимуму.

Зазначимо, що об'єднуючим асоціативним компонентом у творах сучасної американської й британської художньої прози є побудова гармонійних стосунків між поколіннями батьків і дітей, пошук виходу з моральної кризи: We pretend that we know our children, because it's easier than admitting the truth, they are strangers. It's far easier to tell yourself your daughter is still a little girl than to see her in a bikini and realize she has the curves of a young woman; it's safer to say you are a good parent who has all the right conversations about drugs and sex than to acknowledge there are a thousand things she would never tell you [27]. Героїня визнає свою слабкість, маскуючи страх перед реальними проблемами у вихованні доньки (pretend that we know our children). Зміст висловлювання спонукає до висновку, що на сучасному етапі школа і сім'я втрачають авторитарні функції у свідомості молоді. Це веде до внутрішньо-особистісного протистояння і конфлікту зі старшим поколінням, яке сприймається вороже (they are strangers). Способи вираження молоддю ідентичності не вписуються у рамки колишньої панівної культури. Такі аргументи доводять наявність асоціативного зв'язку між концептами МОЛОДІСТЬ і ПРОТЕСТ.

Отже, проведений інтерпретаційно-текстовий аналіз загальної вибірки (658 фрагментів) дає змогу визначити асоціативний потенціал концепту МОЛОДІСТЬ. Кількісний розподіл даних представлено на рис. 1 (частотність кореляцій зі 100 \%).

Відзначимо, що у більшості випадків асоціативні кореляції з кількома концептами одночасно накладаються та переплітаються, активізуючись у рамках одного текстового 


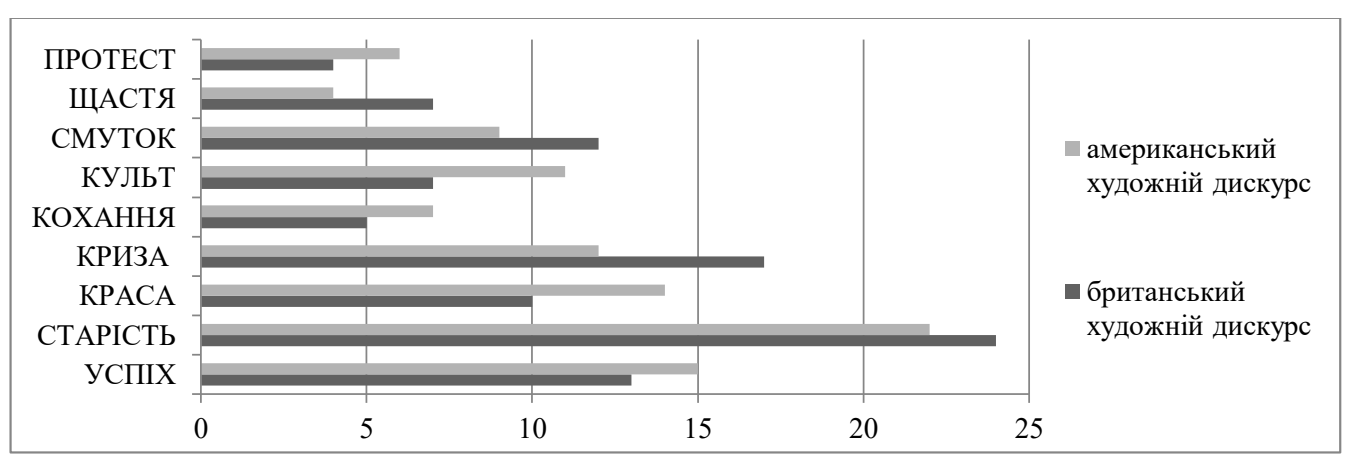

Рис. 1. Розподіл асоціативних кореляцій концепту.

фрагменту при зіставленні ознак молодості і старості. Тому запропоновані кількісні дані відтворюють загальні тенденції та відмінності актуалізації досліджуваного концепту на лінгвокультурному рівні. Відтак, одержані показники частотності вказують на переважно позитивний аксіологічний вектор портретування молодості у творах сучасних американських авторів у порівнянні 3 творами британських письменників, де ця вікова категорія постає у негативній асоціативній аурі. Спільним аспектом $є$ тісна кореляція 3 концептом СТАРІСТЬ, на тлі якої виформовується цілісний асоціативний діапазон концепту МОЛОДІСТЬ.

Висновки та перспективи подальших досліджень. Концепт не $є$ застиглим фрагментом дійсності; під упливом суспільних факторів зазнає перевтілень у літературних творах, а тому слугує основою для кількох шарів асоціацій, якими різні суб'єкти дискурсу оперують залежно від низки соціокультурних і суто індивідуальних характеристик (від соціального статусу і професії до сфери інтересів і смаків). Безперечно, у площині художнього тексту представлення й осмислення дійсності опосередковані задумом автора, його мистецьким баченням, уявленнями літературної епохи і жанровими конвенціями. Тому зауважимо, що у рамках цього дослідження ми вивчали концепт МОЛОДІСТЬ не загалом, а виключно його репрезентацію у художніх творах, написаних сучасними британськими й американськими письменниками протягом 2005-2015 pp.

Асоціативний потенціал концепту МОЛОДІСТЬ вміщує смислові кореляції 3 концептами СТАРІСТЬ, УСПІХ, КРАСА, КРИЗА, КОХАННЯ, КУЛЬТ, СМУТОК, ЩАСТЯ, ПРОТЕСТ.

Виявлені асоціативні зв'язки можна представити у вигляді асоціативних ланцюжків з чітким аксіологічним маркуванням. Позитивна аксіологія: МОЛОДІСТЬ $\rightarrow$ необмежені ресурси $\rightarrow$ кар'єрний ріст $\rightarrow$ конкурентоспроможність $\rightarrow$ бажання рухатись вперед $\rightarrow$ втілення задумів $\rightarrow$ достойна самооцінка $\rightarrow$ віра у себе. Негативна аксіологія: МОЛОДІСТЬ $\rightarrow$ заперечення старості $\rightarrow$ криза особистості через втрату молодості або неспроможність ї̈ зберегти $\rightarrow$ внутрішньо-особистісний конфлікт $\rightarrow$ перші розчарування $\rightarrow$ конфлікт поколінь $\rightarrow$ агресивне ставлення до cвіту. Частково імплікований/експлікований низкою контекстів, такий асоціативний 
діапазон є проекцією на наявні системи цінностей, норми поведінки, дотичні до вікової категорії молодості в англомовній спільності. На семантичному рівні варіювання асоціативного змісту концепту представлене зміною значення молодості, яка сприймається вже не стільки як вікова категорія, а як суспільно-рольова ознака та атрибут зовнішності.

Результати проведеного дослідження дають змогу окреслити перспективи подальшого комплексного вивчення концепту МОЛОДІСТЬ у площині інших типів дискурсу, висвітлення гендерних особливостей його актуалізації, а також аналізу інших концептів вікової парадигми, зокрема, у порівняльному аспекті.

\section{СПИСОК ВИКОРИСТАНОЇ ЛІТЕРАТУРИ}

1. Бахмет О. В. Языковая актуализация оценки геронтологических преобразований личности (на материале английского языка): автореф. дисс. ... канд. филол. наук : 10.02.04. Санкт-Питербург, 2006. 22 с.

2. Бехта I. А. Функційно-прагматична дієвість тексту у світлі когніції й дискурсу. Людина. Комп'ютер. Комунікачія. Збірник наукових працьь. Львів : Львівська політехніка, 2013. № 21 C. 99-103.

3. Власова К. А. Словообразовательные гнезда “молодой - старый” в русском языке (опыт сопоставительного анализа): автореф. дисс. ... канд. филол. наук : 10.02.04. Новгород, 2002. $21 \mathrm{c}$.

4. Волков Б. С. Психология юности и молодости. Москва : Академический проект, 2006. $347 \mathrm{c}$.

5. Волкоморова О. Б. Лексика возрастной стратификации в русском языке и речи: автореф. дисс. ... канд. филол. наук : 10.02.10. Тюмень, 2006. 20 с.

6. Воркачев С. Г. Вариативные и ассоциативные свойства теленомных лингвоконцептов. Волгоград : Парадигма, 2005. 428 с.

7. Коновалова Ю. С. Фразеологизмы, паремии и афоризмы как средство объективации возрастных концептов в англо-американской языковой картине мира : автореф. дисс. ... канд. филол. наук : 10.02.04. Воронеж, 2012. 22 с.

8. Крючкова Н. В. Концепты возраста (на материале русского и французского языков) : автореф. дисс. ... канд. филол. наук : 10.02.00. Саратов, 2003. 20 с.

9. Мартинюк А. П. Словник основних термінів когнітивно-дискурсивної лінгвістики. Харків : ХНУ імені В. Н. Каразіна, 2012. 109 с.

10. Осовська I. М. Сучасний німецькомовний сімейний дискурс: ментальний і вербальний ресурс : монографія. Чернівці : Видавничий дім “РОДОВІД”, 2013. 403 с.

11. Пинтова А. А. Пословичные концепты old / старый и young / молодой в английской и русской языковых картинах мира. Проблемы идиоэтнической фразеологии. СанктПитербург : Изд-во РГПУ им. А. И. Герцена. 2007. №4 (7). С. 57-60.

12. Погораева Е. А. Концепт Jugend и его языковая онтология в лексикосемантической системе современного немецкого языка: лингвокультурологический и социолингвистический аспекты : автореф. дисс. ... канд. филол. наук : 10.02.00. Иркутск, 2002. 20 с.

13. Приходько А. М. Концепти і концептосистеми в когнітивно-дискурсивній парадигмі лінгвістики : монографія. Запоріжжя: Прем'єр, 2008. 356 с.

14. Сагатова С. С. Способ выявления социальных стереотипов возраста человека. Русский язык: исторические судьбы и современность. Москва : МГУ, 2004, №3. 
15. Степанов Ю. С. Константы. Словарь русской культуры. Опыты исследования. Москва : Академический проект, 2001. 284 с.

16. Фомина 3. Е., Коновалова Ю. С. Геронтологические категории "Youth" / "Молодость” и "Old age" / "Старость" в англо-американских языковых рефлексиях в аспекте идиосинкразии. Вестник ВГАСУ. Воронеж, 2011. №2 (16), С. 27-43.

17. Щербо П. А. Особенности вербализации концепта “возраст” в системах типологически разных языков: на материале английской, французской и русской лексики : автореф. дисс. ... канд. филол. наук : 10.02.00. Москва : МГЛУ, 2008. 21 с.

18. Эриксон Э. Идентичность: юность и кризис. Москва : Флинта; МПСИ : Прогресс, 2006.

19. Crowther J. Oxford Guide to British and American Culture. Oxford University Press, 2003. $411 \mathrm{p}$.

20. Frith S. The Sociology of Youth. London : Open University Press, 1984. 274 p.

21. Howe N. Millennials Rising: The Next Great Generation. New York : Vintage Books, 2000.

\section{СПИСОК ВИКОРИСТАНИХ ДЖЕРЕЛ}

22. Banks I. Excession. URL: //www.e-reading.co.uk/bookreader.php/134209/ Banks_4 Excession.html

23. Barnes J. The Sense of an Ending. URL: http://english4success.ru/Upload/books/1718.pdf

24. Franzen J. Freedom. URL: http://etextlib.ru/Book/Details/2403

25. Gaiman N. Coraline. URL: https://royallib.com/book/Gaiman_Neil/Coraline.html

26. Mitchell D. Cloud Atlas. URL: https://royallib.com/book/Mitchell_David/Cloud_Atlas.html.

27. Picoult J. Picture Perfect. URL: http://www.general-ebooks.com/read/347398.

28. Sparks N. The Lucky One. URL: https://royallib.com/book/Sparks_Nicholas/The_Lucky_ One.html

29. Steel D. Happy Birthday. URL: https://royallib.com/book/Steel_Danielle/Happy_Birthday_A_ Novel.html

\section{REFERENCES}

1. Bahmet O. V. Yazykovaya aktualizaciya ocenki gerontologicheskih preobrazovanij lichnosti (na materiale anglijskogo yazyka) [Language evaluation of gerontological personality transformations (based on the English language)]: avtoref. diss. kand. filol. nauk. 10.02.04. Sankt-Piterburg, 2006.

2. Bekhta I. A. Funktsiino-prahmatychna diievist tekstu u svitli kohnitsii y dyskursu [Pragmatic function of the text in the light of cognition discourse]. Liudyna. Kompiuter. Komunikatsiia. Zbirnyk naukovykh prats. Lviv : Lvivska politekhnika, 2013. P. 99-103.

3. Vlasova K. A. Slovoobrazovatel'nye gnezda "molodoj - staryj” v russkom yazyke (opyt sopostavitel'nogo analiza) [Word-building pairs 'young - old' in Russian (a comparative analysis)]: avtoref. diss. kand. filol. nauk. 10.02.04. Novgorod, 2002.

4. Volkov B. S. Psihologiya yunosti i molodosti [Psychology of Adolescence and Youth]. Moskva : Akademicheskij proekt, 2006. 
5. Volkomorova O. B. Leksika vozrastnoj stratifikacii v russkom yazyke i rechi [Age stratification in Russian vocabulary and speech]: avtoref. diss. kand. filol. nauk. 10.02.10. Tyumen, 2006.

6. Vorkachev S. G. Variativnye i associativnye svojstva telenomnyh lingvokonceptov [Variational and Associative Properties of Telenomic Linguistic Concepts]. Volgograd : Paradigma, 2005.

7. Konovalova Yu. S. Frazeologizmy, paremii i aforizmy kak sredstvo ob'ektivacii vozrastnyh konceptov v anglo-amerikanskoj yazykovoj kartine mira [Idioms and aphorisms as a means of objectifying age concepts in the Anglo-American language picture of the world]: avtoref. diss. kand. filol. nauk. 10.02.04. Voronezh, 2012.

8. Kryuchkova N. V. Koncepty vozrasta (na materiale russkogo i francuzskogo yazykov) [Age concepts (based on Russian and French languages)]: avtoref. diss. kand. filol. nauk. 10.02.00. Saratov, 2003.

9. Martyniuk A. P. Slovnyk osnovnykh terminiv kohnityvno-dyskursyvnoi linhvistyky [Glossary of the Main Terms of Cognitive-Discursive Linguistics]. Kharkiv : KhNU imeni V. N. Karazina, 2012.

10. Osovska I. M. Suchasnyi nimetskomovnyi simeinyi dyskurs: mentalnyi i verbalnyi resurs [Modern German Family Discourse: Mental and Verbal Resources]. Chernivtsi : Vydavnychyi dim "RODOVID", 2013.

11. Pintova A. A. Poslovichnye koncepty old / staryj i young / molodoj v anglijskoj i russkoj yazykovyh kartinah mira [Proverbial concepts old and young in English and Russian language pictures of the world]. Problemy idioetnicheskoj frazeologii [Problems of Idioethnic Phraseology]. Sankt-Piterburg : Izd-vo RGPU, 2007. №4 (7), P. 57-60.

12. Pogoraeva E. A. Koncept Jugend i ego yazykovaya ontologiya v leksikosemanticheskoj sisteme sovremennogo nemeckogo yazyka: lingvokul'turologicheskij i sociolingvisticheskij aspekty [The concept 'Jugend' and its linguistic ontology in the lexico-semantic system of the modern German language: linguocultural and sociolinguistic aspects]: avtoref. diss. kand. filol. nauk. 10.02.04. Irkutsk, 2002.

13. Prykhodko A. M. Kontsepty i kontseptosystemy v kohnityvno-dyskursyvnii paradyhmi linhvistyky [Concept and Concept Systems in the Cognitive-Discursive Paradigm of Linguistics]. Zaporizhzhia : Premier, 2008.

14. Sagatova S. S. Sposob vyyavleniya social'nyh stereotipov vozrasta cheloveka [A way to identify social stereotypes of a person's age]. Russkij yazyk: istoricheskie sud'by i sovremennost'. Moskva : MGU, 2004.

15. Stepanov Yu. S. Konstanty. Slovar' russkoj kul'tury. Opyty issledovaniya [Constants. Dictionary of Russian Culture. Research Experiences]. Moskva : Akademicheskij proekt, 2001.

16. Fomina Z. E., Konovalova Yu. S. Gerontologicheskie kategorii "Youth"/"Molodost"” i "Old age"/"Starost" v anglo-amerikanskih yazykovyh refleksiyah v aspekte idiosinkrazii [Gerontological categories 'Youth' and 'Old age' in Anglo-American linguistic reflections: idiosyncratic aspect]. Vestnik VGASU. Voronezh, 2011. № 2 (16), P. 27-43.

17. Shcherbo P. A. Osobennosti verbalizacii koncepta "vozrast" v sistemah tipologicheski raznyh yazykov: na materiale anglijskoj, francuzskoj i russkoj leksiki [Verbalization of the concept 'age' in systems of typologically different languages: on the basis of English, French and Russian vocabulary]: avtoref. diss. kand. filol. nauk. 10.02.00. Moskva : MGLU, 2008. 
18. Erikson E. Identichnost': yunost' i krizis [Identity: adolescence and crisis]. Moskva : Flinta; MPSI : Progress, 2006.

19. Howe N. Millennials Rising: The Next Great Generation. New York : Vintage Books, 2000.

20. Frith S. The Sociology of Youth. London : Open University Press, 1984.

21. Crowther J. Oxford Guide to British and American Culture. Oxford : Oxford University Press, 2003.

\title{
SOURCES
}

22. Banks I. Excession. URL: //www.e-reading.co.uk/bookreader.php/134209/ Banks_4 Excession.html

23. Barnes J. The Sense of an Ending. URL: http://english4success.ru/Upload/books/1718.pdf

24. Franzen J. Freedom. URL: http://etextlib.ru/Book/Details/2403

25. Gaiman N. Coraline. URL: https://royallib.com/book/Gaiman_Neil/Coraline.html

26. Mitchell D. Cloud Atlas. URL: https://royallib.com/book/Mitchell_David/Cloud_Atlas.html.

27. Picoult J. Picture Perfect. URL: http://www.general-ebooks.com/read/347398.

28. Sparks N. The Lucky One. URL: https://royallib.com/book/Sparks_Nicholas/The_Lucky_ One.html

29. Steel D. Happy Birthday. URL: https://royallib.com/book/Steel_Danielle/Happy_Birthday_A_ Novel.html

\section{ASSOCIATIVE POTENTIAL OF THE CONCEPT YOUTH (IN CONTEMPORARY ENGLISH LITERARY DISCOURSE)}

\section{Olga Beshlei}

\author{
Yuriy Fedkovych Chernivtsi National University, \\ 2, Kotsubynskogo Str., Chernivtsi, Ukraine, 58012 \\ o.beshlei@chnu.edu.ua
}

The article explores the associative meaning of the concept YOUTH in contemporary English literary discourse. The significance of the research is justified by a general interest of linguistic studies in the cognitive analysis of the verbalized knowledge structures. Defined as a discrete mental unit, the concept YOUTH is one of the basic categories within the framework of age semantics and is characterized by extensive associative-axiological potential as well as by the variability of its meaning. In the present study, youth is viewed as an ageing period that has a particular socio-cultural value. Therefore, transformations in the current associations and experiences connected to the essence of youth stipulate the need for its literary reinterpretation. The article aims at specifying the associative correlations between the concept YOUTH and other basic, emotional, socio-cultural and aesthetic concepts in contemporary British and American prose. The research integrates the methods of cognitive semantics, descriptive analysis and quantitative analysis. Textual interpretation aims at revealing implicit/explicit associations and experiences situationally related to youth as an age category. The obtained data clarify the relationship between linguistic expression of the 
concept YOUTH and the human perception of reality, which is traced in its axiological variability. A close correlation between YOUTH and OLD AGE stipulates the formation of further associative links with the concepts of SUCCESS, BEAUTY, CRISIS, LOVE, CULT, SADNESS, HAPPINESS, and PROTEST. The results explicate common components in the associative meaning, among them: a desire to keep / regain youth, sharp rejection of old age, inability to preserve youthful beauty, the tragedy of its loss, personality crisis, and generation gap. The concept is not a stable fragment of reality. Under the influence of social factors, it serves as a basis for several layers of associations. Partly implicated in contemporary prose, the associative potential of the concept YOUTH is a projection on existing system of values and norms of behaviour, relevant to this ageing period within the English-speaking community. At the semantic level, the variability of the concept's associative meaning is represented by a shift in the perception of youth not so much as an age category but rather as a social role feature or the attribute of appearance.

Key words: associative correlations, concept, literary discourse, implicit/explicit meaning, axiological connotation. 